\title{
Design, Fabrication and Testing of Programmable LEGO VD Graaf Generators for Innovative STEM Education
}

\author{
Dean M. Aslam ${ }^{1}$, Sean Hatch ${ }^{2}$ and Cyrous Rostamzadeh ${ }^{3 *}$ \\ BioMEMS and Mind Laboratory, Electrical and Computer Engineering Department \\ Michigan State University, E. Lansing, MI 48824, \\ * Robert Bosch LLC, EMC Department, Plymouth, MI 48170³
}

\begin{abstract}
The Technology Assisted Science, Engineering and Mathematics (TASEM) learning, with major focus on innovations in the use of technology to explain new and complicated concepts rather than on education research, goes far beyond the conventional demos of van de Graaf (VDG) generators to introduce programmable Lego-based VDG (PLVDG) for the first time. The PLVDG modules explain underlying concepts of micro- and nano-systems in a fun and fascinating way as evident from the level of interest seen in over 2000 learners at K-12, undergraduate and graduate levels during 2000-2010. The interest in PLVDG seems to be strongly related to the fact that the learners can design, build, program and explore PLVDG using different pulley \& belt materials and a palm-size robot. The generated voltages are in the range of 5-35 kV depending upon humidity and pulley speed. Sensors of positive and negative charges have also been developed using NMOS and PMOS switches embedded in LEGO-like bricks. Several new experiments are reported in this paper focusing on learning of a number of areas including materials, engineering (EE \& ME), computers, and microsystems.
\end{abstract}

\section{INTRODUCTION}

The prevalence of new technologies in old and new consumer products emphasizes the need to explain to both the formal and informal learners about (a) technologies that are in the market today as well as those that will be there in near future and (b) how these technologies are used to build micro- and nano-systems. As the explanation of the underlying concepts in new technologies can be very challenging, traditionally efforts to increase impact of informal as well as formal learning techniques have focused on a restructuring of school science around real-world problems [1], inquiry based studies [2][3][4][5] including Design-Based Science (DBS) [6][7][8][9][10][11][12][13][14][15] and Learning By Design (LBD) [16][17][18], Augmented Reality (AR) [19][20][21][22][23][24][25], and Technology Assisted Science, Engineering and Mathematics (TASEM) [26][27][28]. A unique feature of the TASEM program is that it, encompassing number of inquiry-based hands-on ideas, focuses on current and future technologies capable of dealing with a variety of learning concepts and environments [29][30][31][32][33][34][35][36][37][38][39].

Wall-climbing robots [40] and Microsystems courses have also been developed [41][42]. Because TASEM [26][27][28] is based on technology, it can address (a) technological learning issues in a unique way and (b) attempt very difficult and dry topics. One example is the explanation of a microcontroller $(\mu \mathrm{C})$, its building blocks, and their fabrication/operation. Recently, intriguing aspect of Functionalized Bricks with Embedded Intelligence (FBEI) have focused on creative aspects of K-16 education [43][44]. Commercially available VD Graaf (VDG) generators are available for STEM learning but users, in most cases, can't modify or build them.

This paper focuses on design, fabrication and testing of programmable LEGO VDG generators for innovative STEM education. Concepts discussed are (a) design of VDG, (b) miniaturization, (c) static charge sensors, (d) energy scavenging from static charges, (e) VDG designs and miniaturization, (f) VDG discharge currents measurement, and (g) demonstration of microsystems operational princilpes. Such research-oriented education ideas are unique in the world [44].

\section{VDG BASICS}

The VDG generator, developed in 1929 [45], is the twentieth century's contribution to the lineage of static electricity. In 1933, VDG machine, that produced 1 million volts, was only a few feet tall [45]. VDG generators have been used in the fields of nuclear research [46][47][48] and medical radiations [49]. VDG Generators have also been used for fun and science experiments. A Frankenstein demonstration [50], induction and repulsion with soap bubbles [51], and candle on a VDG [52] are some examples of early experiments.

A VDG is an electrostatic machine which uses a moving belt to generate very high voltages (in the range of $5-35$ thousand volts for toy VDG and up to 14 million volts for commercial VDG) on a hollow metal globe. Fig. 1 shows how 


\section{International Journal of Advanced Research in Computer and Communication Engineering}

Vol. 10, Issue 6, June 2021

DOI 10.17148/IJARCCE.2021.10601

the positive and negative charges are separated and transferred to globe and the ground electrode, respectively. For example, if the lower pulley is made of ebonite or Teflon the process of rubbing will make it negative inducing a positive charge on the outside surface of the belt. As the belt moves up it brings the positive charge to the brush that picks it up through sparking. Because the like-charges repel each other they move to the outside surface of the globe (which is made from a conducting material such as a metal) where there is a larger surface area available making it possible for them to stay away from each other as shown in Fig. 1 (b).

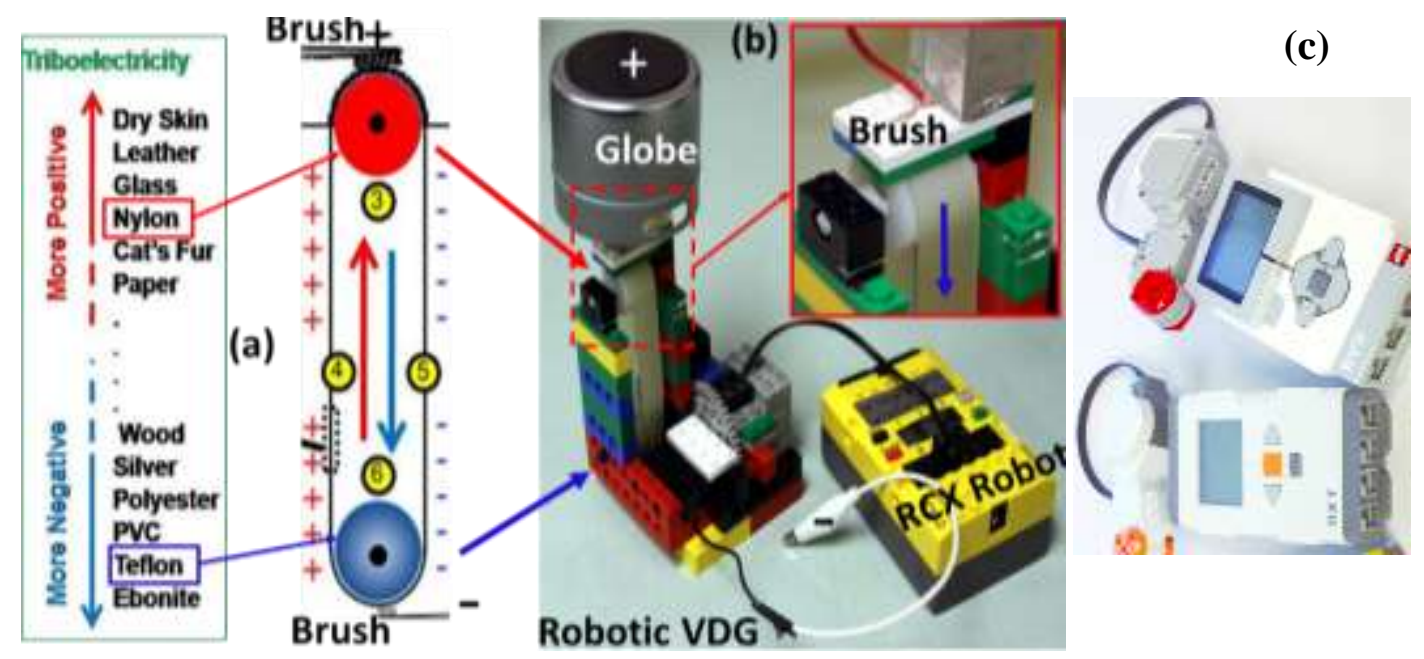

Fig. 1 VDG details; (a) schematic, (b) RCX LEGO based VDG, and (c) NXT \& EV3 robots.

If the upper pulley is made from leather or nylon, a similar process will transfer negative charge to the negative electrode, usually connected to ground.

The charges on the globe lead to an electrostatic voltage which depends on humidity level, pulley materials, belt speed and globe size. There is a theoretical maximum potential to which a VDG dome can be raised [53].

For the first time, this paper reports the design, fabrication, and testing of toy VDG generators using plastic bricks, like LEGO. Except for belt, the pulleys and globe, which are custom made to fit the LEGO brick construction, all parts are made using commercially available bricks, plates, beams, axles, LEGO motors, and Robotics Invention System. Fig. 1 shows the first version of a robotic VDG.

\section{MACRO, MICRO AND NANO STRUCTURES}

Fig. 2 shows dimensions and miniaturization concepts that are important for miniaturization of VDGs as shown in Fig. 3. It is interesting to look at a broader definition of small structures with unusual properties. While the minimum conductive lengths in transistors in the latest microprocessors are at $5 \mathrm{~nm}$ level, these lengths in future processors are expected to be less than this. Can such lengths get smaller than $1 \mathrm{~nm}$ ? Is it possible to define physical properties for particles at $1 \mathrm{~nm}$ or smaller? At such small length scales it is also important to consider the number of atoms. For the calculation of density of atoms in a particle of cubic shape, it is assumed that there is one atom in the cube if its dimension is $100 \mathrm{pm}$. As one needs a certain minimum number of atoms in a particle to calculate its physical properties, an important question is: At what smallest level, length or number of atoms, it becomes impossible to define the physical properties? It is found that if the particle size is less than approximately $1-2 \mathrm{~nm}$ or $1000-2000 \mathrm{pm}$, the physical properties cannot be defined. Based on number of atoms in a particle, the structures with dimensions around 1000 pm or less can be defined as pico-structures and the technology

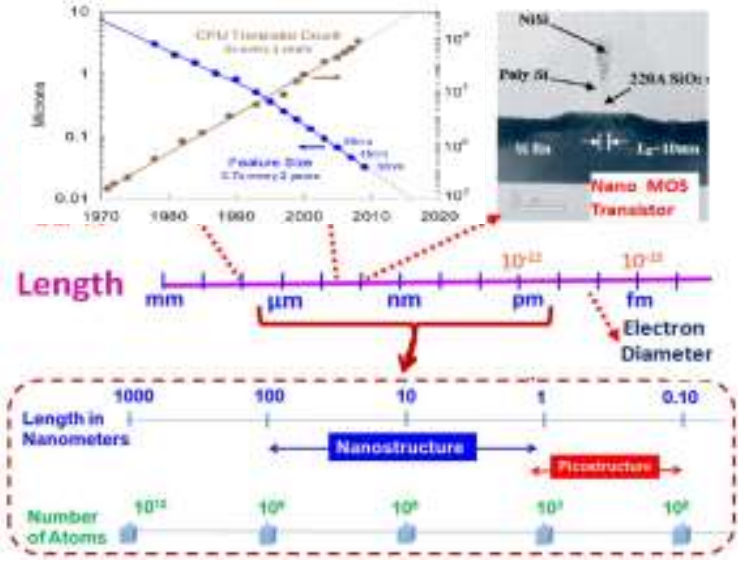

Fig. 2 Dimensions and miniaturization. needed to fabricate them as pico-technology (see Fig. 2).

As shown in Fig. 3, this research developed VDGs of different sizes that use LEGO based structures that were all tested and demonstrated to K-12 audiences during 2005 - 2016. To create excitement, soap bubbles were used (as shown in Fig. 


\section{International Journal of Advanced Research in Computer and Communication Engineering}

Vol. 10, Issue 6, June 2021

DOI 10.17148/IJARCCE.2021.10601

4). The bubbles were charged by VDGs and if they carry similar charges, they repel one another. Fig. 3 shows internal components, miniaturization, and testing of VDG generators.

III.1 Computer Switches Sense Positive and Negative Charges: The NMOS and PMOS switches can also help study static charges and understand their adverse effects on microcontrollers and microprocessors. For example, static charges generated on the human body present in a car can damage car's computer circuits and make it non-functional even if its engine and other mechanical parts are still functional.

The mightiest display of static charges is found in lightening. For the first time, the TASEM program uses Programmable Lego-based Van de Graaff (PLVDG) generators to learn about static charges, NMOS and PMOS switches, static charge sensors, system design and fabrication, and microstructures. The PLVDG modules explain the underlying concepts of micro- and nano-systems in a fun and fascinating way as evident from the level of interest seen in over 10,000 learners at K12, undergraduate and graduate levels during 2000-202.

A microcontroller is a computer chip that is the brain of today's consumer products including those based on micro- and nano-systems. It is a computer-on-a-chip suitable for applications that require high integration, low power consumption, and low cost.

An electrostatic switch, called an MOS (Metal Oxide Semiconductor) transistor, is the basic building block of a microcontroller. Using the basic MOS concept different types of computer switches are made and explained to K-12 learners

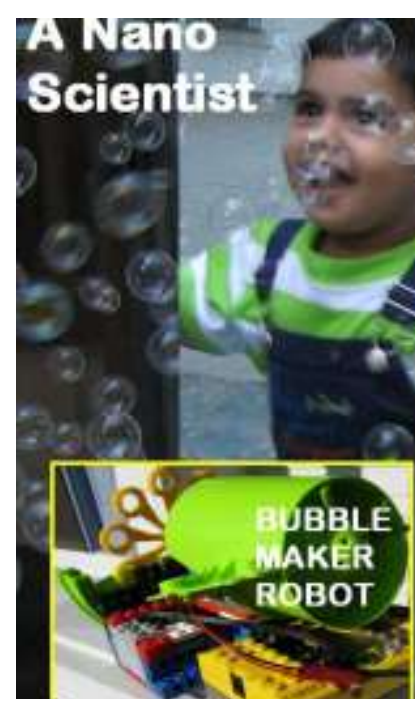

Fig. 4 The eyes of this twoyear old boy mirror a level of excitement that can only be indebted to the $200 \mathrm{~nm}$ thick skin of soap bubbles.
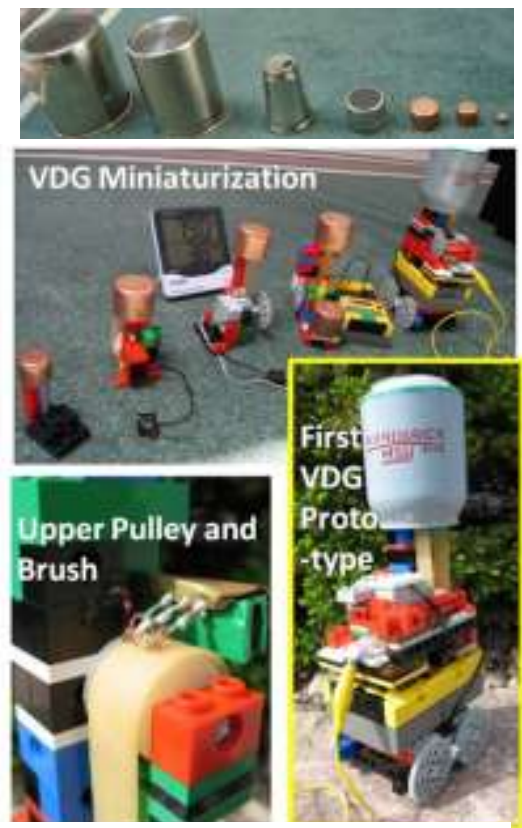

Fig. 3 VDG miniaturization. [43] as shown in Fig. 5, which are needed for computing and memory devices. Some examples are n-channel MOS (NMOS), PMOS (p-channel), and CMOS (a complementary combination of NMOS and PMOS) as explained in Fig. 5 (C). As an NMOS switch is operated by a positive static charge and a PMOS switch is operated by negative static charge, they can be used as inexpensive sensors for static charges. That also means that NMOS and PMOS switches can be used to switch number of other devices such as beepers, motors, fans, toys, etc. Such simple and inexpensive devices can be fun to play with on one hand and can help learn science, technology, engineering, and mathematics (STEM) on the other.
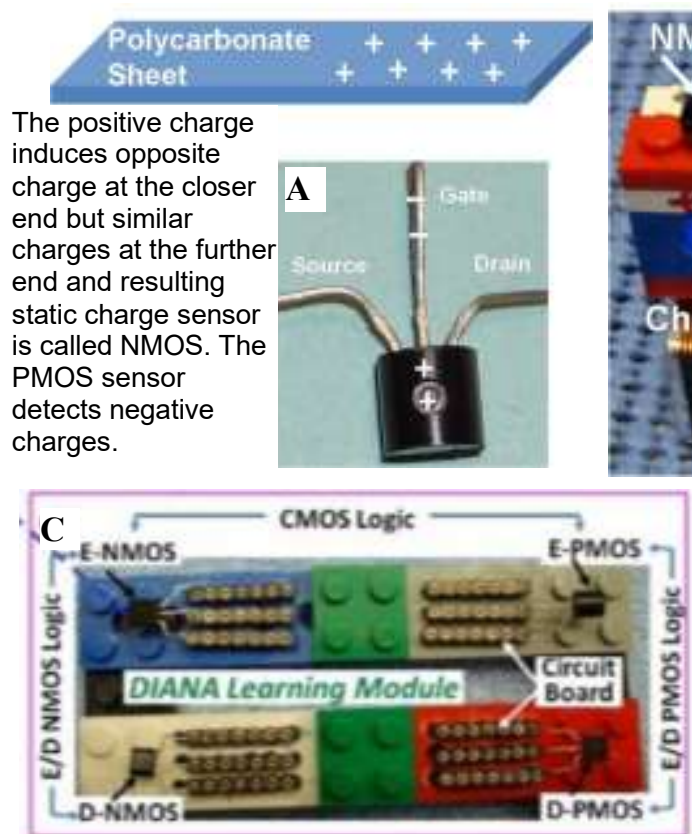

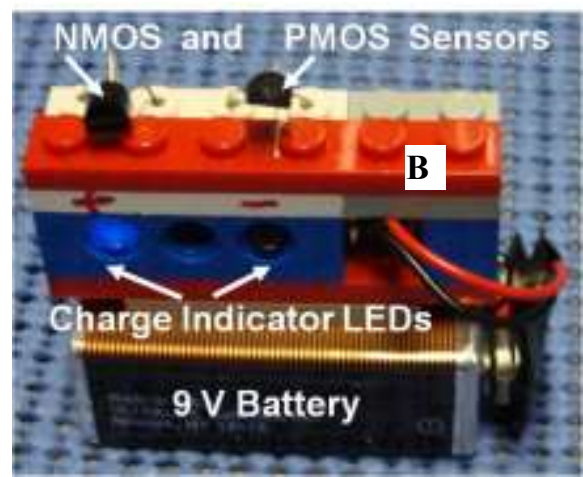

Fig. 5: Computer switches as static-charge sensors; positive charge sensor (A), LEGO-embedded sensor for positive and negative charges (B) and logic types (C). 


\section{ENERGY SCAVENGING FROM STATIC CHARGES}
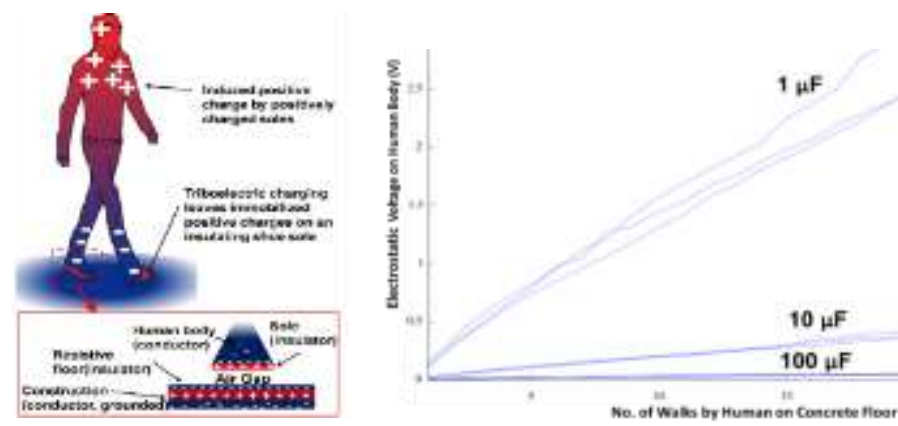

Fig. 6: Energy scavenging from static charges using ceramic

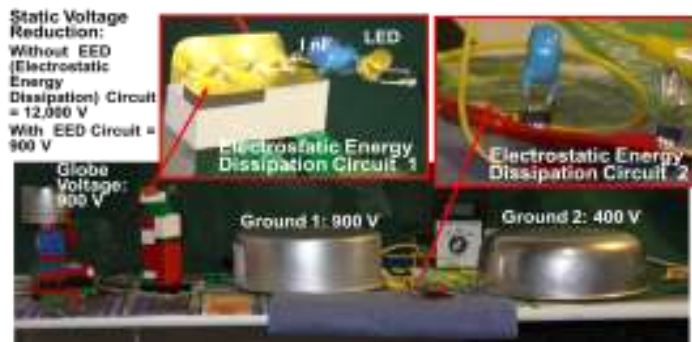

Fig. 7: Energy scavenging from static charges using ceramic capacitors.

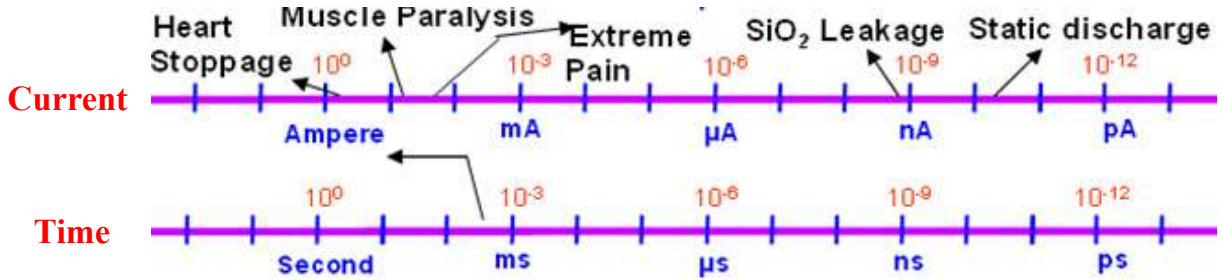

Fig. 8: Currents in human body; static charge current is too low to harm the body.
Energy scavenging from static charges using energy storage in ceramic capacitors is shown in Fig. 6 that shows energy scavenging from human body. A human, wearing shoes with insulating soles, walks on carpet back and forth charging the body and then touches one terminal of ceramic capacitor (the other is grounded). The curves in Fig. 6 show body voltage as a function of number of walks for 1,10 and $100 \mu \mathrm{F}$ ceramic capacitors. Based on $\mathrm{Q}$ $=\mathrm{CV}$, the larger capacitor values result in less voltages for the same Q.

The electrostatic discharge currents do not harm the human body because discharge currents are less than $100 \mathrm{pA}$ range as shown in Fig. 8. The currents that cause pain and muscle damage are in the range of $10-100 \mathrm{~mA}$. The heart stops for currents above approx. $300-400 \mathrm{~mA}$ range.

VDG discharge currents for different globe sizes were measured at Bosch facility and the results are shown in Fig. 9 for 4 different globe types. The high discharge currents are present below10 ns as shown in Fig. 9. Electrostatic Discharge (ED) current is a double-exponential decaying waveform which can be described analytically as shown in Fig. 10, where $\tau_{1}, \tau_{2}, \tau_{3}, \tau_{4}, v, I_{1}$ and $I_{2}$ are defined in Table 1

Fig. 11 illustrates ESD current waveform for a $25 \mathrm{kV}$ discharge.

This agrees well with ESD IEC reference current waveform as shown in Fig. 12. IEC Reference Waveform defines a discharge of $8 \mathrm{kV}$, hence peak current is lower. ESD of a Human Body Model (HBM) charged to $25 \mathrm{kV}$ would release approximately $30 \mathrm{~mJ}$ of energy. HBM is typically a $150 \mathrm{pF}$ capacitance $\left(E=\frac{1}{2} \mathrm{CV}^{2} \approx 30 \mathrm{~mJ}\right)$. Also one may use expression for ESD current waveform as defined earlier with a discharge on a $2-\Omega$ ESD target impedance $\int_{0}^{t} i^{2}(t) d t$ to evaluate the energy content due to a single ESD event.

Table 1

\begin{tabular}{|c|c|c|c|}
\hline$I_{l}=21.9 \mathrm{Amp}$ & $t_{J}=1.3 \mathrm{~ns}$ & $t_{3}=6 \mathrm{~ns}$ & $\mathrm{n}=3$ \\
\hline$l_{2}=10.1 \mathrm{Amp}$ & $t_{2}=1.7 \mathrm{~ns}$ & $t_{\mathrm{d}}=58 \mathrm{~ns}$ & \\
\hline
\end{tabular}

$$
\begin{aligned}
& i(t)=\frac{i_{1}}{k_{1}} \cdot \frac{\left(\frac{t}{\tau_{1}}\right)^{n}}{1+\left(\frac{t}{\tau_{1}}\right)^{n}} \cdot \exp \left(\frac{-t}{r_{2}}\right)+\frac{i_{2}}{k_{2}} \cdot \frac{\left(\frac{t}{r_{3}}\right)^{n}}{1+\left(\frac{t}{r_{3}}\right)^{n}} \cdot \exp \left(\frac{-t}{r_{4}}\right) \\
& k_{1}=\exp \left(-\frac{r_{1}}{r_{2}}\left(\frac{n r_{2}}{r_{1}}\right)^{n \cdot n}\right), \quad k_{2}=\exp \left(-\frac{r_{3}}{r_{4}}\left(\frac{n r_{4}}{r_{2}}\right)^{N n}\right)
\end{aligned}
$$

Fig. 10 Current waveform.

Prior to ESD testing, ESD Gun representing a human body is charged to $25 \mathrm{kV}$. ESD current waveform resulting from a contact discharge on a $2 \Omega$ target impedance is captured and 
recorded utilizing a $3 \mathrm{GHz}$ digitizing Oscilloscope. ESD current waveform should indicate $\tau_{\mathrm{r}}<1$ ns and current signature must conform to the IEC reference waveform.

\section{UNDERSTANDING MEMS:}

Micro and Nano Electro Mechanical Systems (MEMS \& NEMS), using new materials, lead to new applications [54][55]. How can such structures be explained K-12 learners?

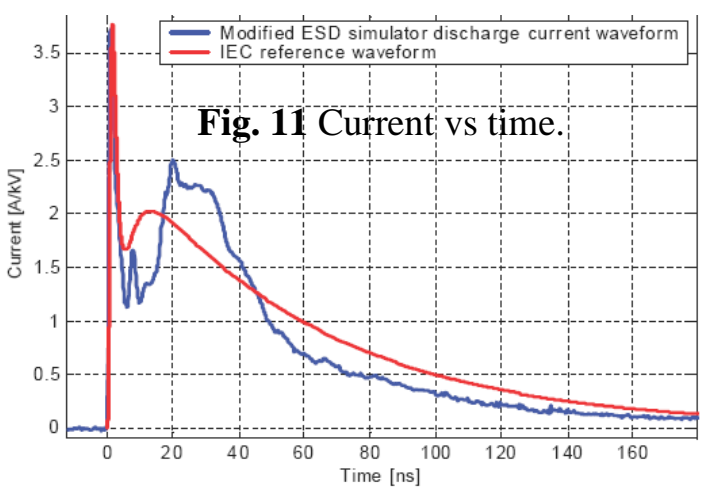

Build a

structure similar to one of the two structures shown in Fig. 13 and measure the spring constant of the movable plate. Use this spring constant to measure the electrostatic force needed to move the upper plate to different positions. The plate can be moved using charge from a van de Graff generator which can supply static charges. Fig. 14 shows schematic of a Si cantilever beam.
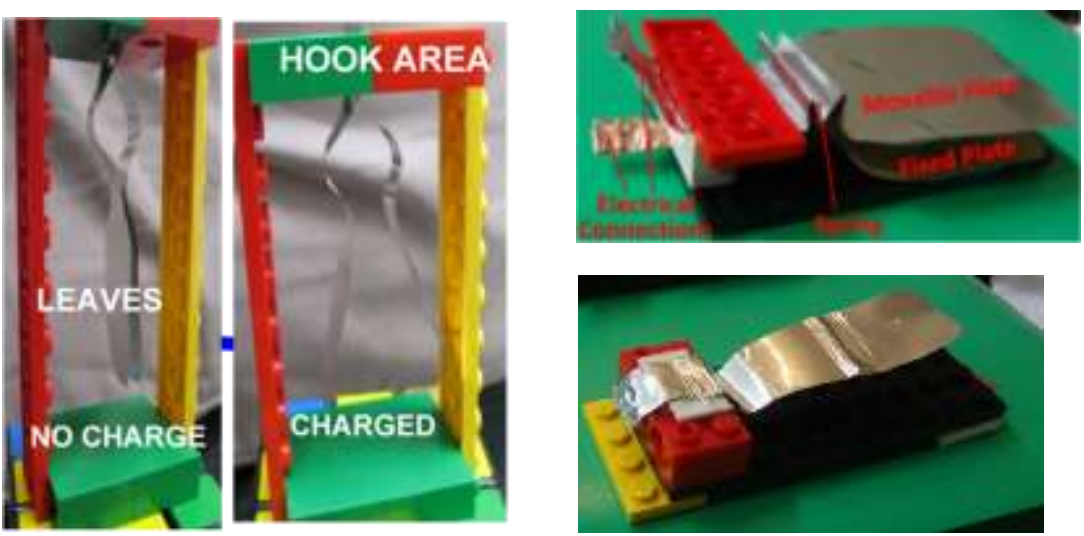

Fig. 13 MEMS functional demos using bigger structures.

Fig. 14 Si cantilever beam.

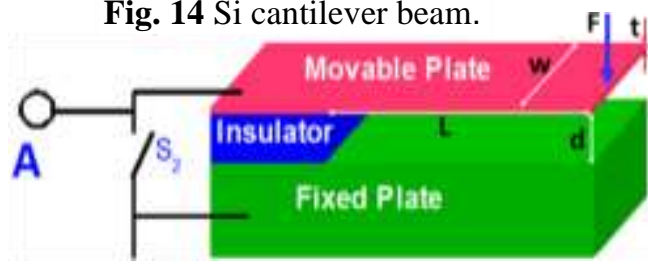

\section{CONCLUSIONS}

To explain new and complicated concepts goes far beyond the conventional demos of van de Graaf (VDG) generators to introduce programmable Lego-based VDG (PLVDG) for the first time. The PLVDG modules explain underlying concepts of micro- and nano-systems in a fun and fascinating way as evident from the level of interest seen in over 2000 learners at K-12, undergraduate and graduate levels during 2000-2016. The interest in PLVDG seems to be strongly related to the fact that the learners can design, build, program and explore PLVDG using different pulley \& belt materials and palmsize robots. The generated voltages are in the range of $5-35 \mathrm{kV}$ depending upon humidity and pulley speed. Sensors of positive and negative charges have also been develop ed using NMOS and PMOS switches embedded in LEGO-like bricks. Several new experiments are reported in this paper focusing on learning of several areas including materials, engineering (EE\&ME), computers, and microsystems. 


\section{International Journal of Advanced Research in Computer and Communication Engineering}

Vol. 10, Issue 6, June 2021

DOI 10.17148/IJARCCE.2021.10601

\section{ACKNOWLEDGEMENT}

This work was partly supported by the Engineering Research Centers Program of the National Science Foundation under Award Number EEC-9986866 during 2000-2010.

\section{REFERENCES}

[1] Lipman, M. (1991). Thinking in education. New York: Cambridge University Press.

[2] CTGV. (1992). The jasper series as an example of anchored instruction: Theory, program description, and assessment data. Educational Psychologist, 27(3), 291-315.

[3] Krajcik, J. S., Blumenfeld, P. C., Marx, R. W., Bass, K. M., Fredricks, J., \& Soloway, E. (1998). Inquiry in project-based science classrooms: Initial attempts by middle school students. The Journal of the Learning Sciences, 7(3\&4), 313-350.

[4] Penner, D. E., Lehrer, R., \& Schauble, L. (1998). From physical models to biomechanics: A design-based modeling approach. The Journal of the Learning Sciences, 7(3\&4), 429-449.

[5] Songer, N.B. (1996). Exploring learning opportunities in coordinated networkenhanced classrooms: A case of kids as global scientists. Journal of the Learning Sciences, 5, 297-328.

[6] D. Fortus, R.C. Dershimer, J. Krajcik, R.W. Marx and R. Mamlok-Naaman, design-based science and student learning, J. Research Sci. Teaching, 41, 1081-1110 (2004)

[7] Roberts, P. (1995). The place of design in technology education. In D. Layton (Ed.), Innovations in science and technology education (pp. 2738). UNESCO.

[8] Baynes, K. (1994). Designerly play. Loughborough, UK: Loughborough University of Technology.

[9] Simon, H.A. (1999). The sciences of the artificial. Cambridge, MA: MIT Press

[10] Bucciarelli, L.L. (1994). Designing engineers. Cambridge, MA: MIT Press.

[11] Davis, M., Hawley, P., McMullan, B., \& Spilka, G. (1997). Design as a catalyst for learning. Alexandria, VA: Association for Supervision and Curriculum Development.

[12] ITEA. (2002). Standards for technological literacy. Reston, VA: International Technology Education Association.

[13] NRC. (1996). National science education standards. Washington, DC: National Academy Press.

[14] NRC. (2002). Scientific research in education. Washington, DC: National Academy Press. Penner, D.E., Lehrer, R., \& Schauble, L. (1998). From physical models to biomechanics: A design-based modeling approach. Journal of the Learning Sciences, 7, 429-449.

[15] Chiapetta, E.L., Koballa, Jr., T.R., \& Collette, A.T. (2002). Science instruction in the middle and secondary schools (5th ed.) Upper Saddle River, NJ: Prentice-Hall.

[16] Kolodner, J.L. (1993). Case-based reasoning. San Mateo, CA: Morgan Kaufmann.

[17] Kolodner, J.L., Crismond, D., Gray, J., Holbrook, J.K., \& Puntambekar, S. (1998). Learning by design from theory to practice. Presented at the International Conference of the Learning Sciences, Georgia Tech University, Atlanta GA

[18] Barrows, H.S. (1985). How to design a problem-based curriculum for the preclinical years. New York: Springer.

[19] Azuma R. A Survey of Augm.ented Reality. PRESENCE: Teleoperators and Virtual Environments, Vol. 6, No. 4, pp. 355-385, 1997.

[20] Osberg K. Spatial Cognition in the Virtual Environ., Technical R-97-18. Seattle: Human Interface Technol. Lab, 1997.

[21] Rizzo AA, Buckwalter JG, Neumann U, Kesselman C, Thiebaux M, Larson P, and van Rooyen A. The Virtual Reality Mental Rotation Spatial Skills Project. In CyberPsychology and Behavior, 1(2), pp. 113-120, 1998.

[22] Pantelidis, V. S. Reasons to Use Virtual Reality in Education, VR in the Schools 1(1), 1995. URL: http://www.soe.ecu.edu/vr/reas.html (Revised 2000).

[23] Roussos, M., Johnson, A., Moher, T., Leigh, J., Vasilakis, C., and Barnes, C. Learning and Building Together in an Immersive Virtual World. PRESENCE 8(3), pp. 247-263, MIT Press, June 1999.

[24] Winn, W. A Conceptual Basis for Educational Applications of Virtual Reality, Technical Report TR 93-9:

http://www.hitl.washington.edu/publications/r-93-9/, 1993.

[25] Zagoranski, S. and Divjak, S., Use of augmented reality in education, EUROCON 2003, 2, 339-342.

[26] D.M. Aslam, "Micro- and Nano- Technologies in K through Ph.D. Education and Research", Keynote, Second World Congress Biomimetics, Artificial Muscles and Nano-Bio (Nano-Bio 2004) Albuquerque, New Mexico, December 6-8, 2004.

[27] D.M. Aslam, "Small Tech Education", Keynote, High Desert MNT Regional Workshop, TVI Workforce Training Center - Albuquerque, NM, October 12-13, 2004

[28] D.M. Aslam, "Technology Assisted Science, Engineering and Mathematics (TASEM) Education at all Levels Using K-Ph.D. Concept", Proc. ASEE Annual Conference, Chicago, 92, 2006

[29] Heimlich, J., Editorial, Environmental Education Research 11(3): 261-264 (2005).

[30] Dierking, L.D., Ellenbogen, K.M. \& Falk, J., "In Principle, in Practice: Perspectives on a decade of museum learning research (1994-2004)", Science Education 88: S1-3 (2004).

[31] Dierking, L.D.; Cohen Jones, M.; Wadman, M.; Falk, J.H.; Storksdieck, M. \& Ellenbogen, K., "Broadening Our Notions of the Impact of FreeChoice Learning Experiences", Informal Learning Review 55, 1, 4-7 (2002).

[32] Allen, S., "Designs for learning: Studying science museum exhibits that do more than entertain", Science Education 88, S17-33 (2004).

[33] Myers, D. (2003). The nature of computer games: Play as semiosis. New York: Peter Lang Publishing.

[34] Squire, K. (2002). Cultural framing of computer/video games. The International Journal of Computer Game Research 2: 1.

[35] Wright, J.C., Anderson, D.R., Huston, A.C., Collins, P.A., Schmitt, K.L. \& Linebarger, D.L. (2001). The effects of early childhood TV-viewing on learning. In Falk, J.H. (Ed.). Free-choice science education: How we learn science outside of school, pp. 79-92, New York: Teachers College Press.

[36] Ellenbogen, K.M., Luke, J.J. \& Dierking, L.D. (2004). Family learning research in museums: An emerging disciplinary matrix? Science Education 88: $48-58$

[37] Rounds, J. (2004). Strategies for the curiosity-driven museum visitor. Curator 47: 389-412.

[38] Azevedo, F.S. (2004). Serious Play: A comparative study of learning and engagement in hobby practices. Unpublished doctoral dissertation. University of California, Berkeley.

[39] Storksdieck, M., Ellenbogen, K. \& Heimlich, J.E. (2005). Changing Minds? Factors that influence freechoice learning about environmental conservation. Environmental Education Research 11(3): 93-109.

[40] G. Wile and D.M. Aslam, "Design, Fabrication and Testing of a Miniature Wall Climbing Robot Using Smart Robotic Feet", Proc. International Conference on Cybernetics and Information Technologies, Systems and Applications, Edited by M. Saavoie et al.,Vol. III, 87-92 (2007). 


\section{International Journal of Advanced Research in Computer and Communication Engineering}

Vol. 10, Issue 6, June 2021

DOI 10.17148/IJARCCE.2021.10601

[41] L. C. McAfee, K. Najafi, Y. Gianchandani, K. D. Wise, and M. M. Maharbiz, D.M. Aslam, P. Bergstrom, C. Friedrich," "MEMS and Microsystems Courses with National and International dissemination", Proc. ASEE Annual Conference, Chicago, 84, 2006.

[42] L. C. McAfee, K. Najafi, Y. Gianchandani, K. D. Wise, and M. M. Maharbiz, D.M. Aslam, P. Bergstrom, C. Friedrich, "A MEMS/MICROSYSTEM CURRICULUM WITH INTERNATIONAL DISSEMINATION ”, Proc.

Hilton Head, 2006.

[43] D.M. Aslam, "Creative Functionalized Bricks with Embedded Intelligence (FBEI) For Research-Oriented Provocative STEM and Workforce Learning” IJARCCE, Vol. 9 (6), 28-43, 2020; https://ijarcce.com/wp-content/uploads/2020/06/IJARCCE.2020.9605.pdf;DOI 10.17148/IJARCCE.2020.9605.

[44] D.M. Aslam, "Creative Functionalized Bricks with Embedded Intelligence (FBEI) For Research-Oriented Provocative STEM and Workforce Learning”, Keynote 2, 2021 IEEE Integrated STEM Education Conference, March 13, 2021; https://www.ieee-isec.info/day/1/track/Keynote; see keynote 2.

[45] Robert J. Van De Graaff, “The Electrostatic Production of High Voltage for Nuclear Investigations” Phys. Rev., vol. 43, 149, 1933

[46] B. L. Doyle, P. S. Peercy “Technique for profiling $1 \mathrm{H}$ with 2.5-MeV Van de Graaff accelerators" Appl. Phys. Lett. 34, 811 (1979);

[47] MJ Burchell, etc., "Hypervelocity impact studies using the 2 MV Van de Graaff accelerator and two-stage light gas gun of the University of Kent at Canterbury" Meas. Sci. Technol 10 (1999) 41-50

[48] Belli, M. etc., "Proton irradiation facility for radiobiological studies at a 7 MV Van de Graaff accelerator" Nuclear Instruments and Methods in Physics Research Section A, Volume 256, Issue 3, p. 576-580.

[49] Rydin R.A. Engler R.A., "15O and 13N production by Van de Graaff accelerator" Physics in Medicine and Biology, Volume 19, Number 6, 1974, pp. 884-885(2)

[50] James G. Ellingson, “A Frankenstein demonstration wtith the Van de Graaff generator" The Physics Teacher, Volume 26, Issue 7, pp. 446-446 (1988)

[51] Robert Prigo, "Demonstration induction and repulsion with soap bubbles and the Van de Graaff generator" Am. J. Phys. Vol. 44, No. 6, June 1976

[52] Motoji Ikeya, Hiroshi Matsumoto, "Reproduced earthquake precursor legends using Van de Graaff generator: candle flame and dropped nails." Naturwissenschaften 84, 539-541 (1997)

[53] Richard E. Berg, "Van de Graaff Generator: Theory, Maintenance, and Belt Fabrication" Physics Teacher, v28 n5 p281-85 May 1990

[54] Fan et al., "Manufacture and characterization of graphene membranes with suspended silicon proof masses for MEMS and NEMS applications", Microsystems \& Nanoengineering (2020); https://doi.org/10.1038/s41378-019-0128-4, www.nature.com/micronano

[55] O. Auciello and D.M. Aslam, "Review on Advances in Microcrystalline, Nanocrystalline and Ultrananocrystalline Diamond Films-Based Micro/Nano-electromechanical Systems Technologies", J. Mater Sci., January 5, 2021;online publication; file://C:/2020SurfaceBackupAug13/Research/ResearchPapers/PapersInprogress\&Published/MCD\&UNCD-ReviewMEMS/AucielloAslam2021_Article_ReviewOnAdvancesInMicrocrystal_1-25-21.pdf https://doi.org/10.1007/s10853-020-05699-9 